\title{
BMJ Open Telehealth and texting intervention to improve HIV care engagement, mental health and substance use outcomes in youth living with HIV: a pilot feasibility and acceptability study protocol
}

\author{
Angie R Wootton, ${ }^{\circ}$ Dominique A Legnitto, ${ }^{1}$ Valerie A Gruber, ${ }^{2}$ \\ Carol Dawson-Rose, ${ }^{3}$ Torsten B Neilands, ${ }^{1}$ Mallory O Johnson, ${ }^{1}$ Parya Saberi ${ }^{\oplus}$
}

To cite: Wootton AR, Legnitto DA, Gruber VA, et al. Telehealth and texting intervention to improve HIV care engagement, mental health and substance use outcomes in youth living with HIV: a pilot feasibility and acceptability study protocol. BMJ Open 2019;9:e028522. doi:10.1136/ bmjopen-2018-028522

- Prepublication history and additional material for this paper are available online. To view these files, please visit the journal online (http://dx.doi org/10.1136/bmjopen-2018028522).

Received 17 December 2018 Revised 18 June 2019 Accepted 25 June 2019

Check for updates

(C) Author(s) (or their employer(s)) 2019. Re-use permitted under CC BY-NC. No commercial re-use. See rights and permissions. Published by BMJ.

For numbered affiliations see end of article.

Correspondence to Professor Parya Saberi; Parya.Saberi@ucsf.edu

\section{ABSTRACT}

Introduction Youth and young adults living with HIV (YLWH) experience worse clinical outcomes than adults and high rates of behavioural health challenges that impact their engagement in care and adherence to antiretroviral therapy. This study in the San Francisco Bay area aims to evaluate the feasibility, acceptability and preliminary clinical outcomes of a 12-session telehealth counselling series provided to $80 \mathrm{YLWH}$, including education, motivational enhancement and problemsolving around HIV care, mental health, substance use and other challenges. Findings will provide information about benefits and challenges of telehealth counselling for YLWH and will guide the development of new technology-based strategies for care.

Methods and analysis The Youth to Telehealth and Text to Improve Engagement in Care study is a pilot randomised, crossover trial examining the feasibility and acceptability of a telehealth counselling intervention consisting of twelve 2030 min weekly sessions focused on identifying and problemsolving around barriers to HIV care access and adherence and on addressing mental health, substance use and/or other issues. Participants also receive text messages for checkins, appointment reminders and to improve engagement. Participants complete quantitative online surveys at baseline, 4 and 8 months and qualitative exit interviews. Clinical outcomes, including plasma HIV RNA and CD4+ cell count, are collected from medical records. Study staff will explore outcomes of the intervention using quantitative and qualitative methods.

Ethics and dissemination This study and its protocols have been approved by the University of California, San Francisco (UCSF) Institutional Review Board. Study staff will work with the UCSF Center for AIDS Prevention Studies' Community Engagement Core and the Youth Advisory Panel to disseminate results to the community, participants and the academic community.

Trial registration NCT03681145.

\section{BACKGROUND}

Youth and young adults aged 18-29 years living with HIV (YLWH) have unique challenges with HIV diagnosis, access and

\section{Strengths and limitations of this study}

- The use of iterative refinement of the intervention manual throughout this pilot study increases the study's potential impact and acceptability among participants.

- The study's counselling intervention is significant in its integrated HIV and behavioural health focus, which is tailored to the participant's baseline HIV knowledge, mental health status and substance use.

- The use of video chat and text messaging modalities for delivery of HIV engagement, mental health and substance use counselling with youth living with HIV is important, reduces the time burden to the clinician and patient and challenges the current delivery of healthcare.

- By examining the acceptability of a fully online versus hybrid in-person online session delivery, we will be able to determine if this intervention can be offered completely remotely, which will in turn increase the geographic reach for the delivery of this intervention.

- This pilot study is limited due to its small sample size, and the data generated from this study may not be generalisable to older individuals and those not living in the San Francisco Bay Area.

maintenance of care. In 2016, in the USA, youth aged 13-24 years accounted for about $21 \%$ of all new HIV infections. ${ }^{1}$ Among those aged 13-29 years and living with HIV, only $41 \%$ were estimated to be aware of their HIV status. In 2014, of those diagnosed with HIV, only $62 \%$ accessed HIV medical care within the first year; of those, $43 \%$ were retained in HIV care, and 54\% had a suppressed HIV viral load. ${ }^{2}$ Access to care and antiretroviral therapy (ART) is crucial for the health of YLWH; high levels of ART adherence is critical for attaining HIV treatment goals including sustaining suppressed HIV viral 
load, decreasing risk of developing drug-resistant strains of HIV, reducing the risk of HIV transmission to others and improving overall health. ${ }^{3-5}$

Mental health and substance use challenges are prevalent in YLWH, though few studies have been conducted on behavioural health issues in YLWH. One study found that $18 \%$ of YLWH who were in care had clinically significant psychological symptoms such as depression or anxiety. ${ }^{6}$ Another study of 1706 YLWH found that $42.6 \%$ reported mental health concerns at a clinically significant level. Of those reporting these symptoms, only 39.7\% reported receiving mental healthcare services in the past year, and $21.9 \%$ reported taking medications for mental health conditions. ${ }^{7}$ Additionally, in one sample of 12- to 26-year-olds living with HIV, $32 \%$ used tobacco, $27 \%$ used marijuana, 21\% used alcohol, and 22\% used other illicit substances. ${ }^{8}$

Mental health and substance use challenges have been shown to negatively impact HIV medication adherence and clinical outcomes across the continuum of HIV care for YLWH. ${ }^{9}{ }^{10}$ For example, in one systematic review and meta-analysis, those with depression symptoms had $42 \%$ lower likelihood of achieving $80 \%$ or higher ART adherence compared with those without depression. ${ }^{11}$ Another found that of those not taking ART, the odds of reporting clinically significant symptoms were three times as high as those on ART, showing the strong relationship between mental illness symptoms and ART uptake and adherence. ${ }^{12}$ Another review found that depression and anxiety symptoms in YLWH were strongly associated with ART non-adherence. ${ }^{13}$ Additionally, the review found that higher alcohol use in the past week and substance use in the past 3 months were also predictive of poor adherence.

There are few evidence-based counselling interventions for YLWH that address behavioural health factors impacting adherence to HIV care. ${ }^{13}$ Interventions developed for adults have shown to be effective in improving depressive symptoms as a method of improving ART adherence. ${ }^{13}$ However, young adults differ in multiple ways, including their technology use habits, creating an opportunity for the application of technologies to behavioural health interventions.

As $98 \%$ of people aged 18-29 years have a mobile telephone and over $85 \%$ have a smartphone, telephone-based interventions are potentially accessible for the majority of YLWH. ${ }^{14}$ Most traditional counselling interventions are provided in person and a clinical setting; engaging in these counselling sessions may be a barrier for YLWH who experience transportation or financial issues, stigma or shame around accessing treatment or other challenges. ${ }^{15}$ In our formative work, YLWH reported that health-focused mobile interventions could overcome concerns about their ability to effectively and openly communicate with their providers. ${ }^{16}$ One survey similarly found that $60 \%$ of millennials would be interested in video chat interactions with their medical provider instead of attending in-office appointments. ${ }^{17}$
Several HIV care adherence interventions have been developed for individuals living with HIV, though most are for adults of all ages rather than YLWH. Few of the interventions specifically developed for YLWH use telehealth, texting or other mobile technologies as the platform for intervention delivery. ${ }^{18}$ Although these methods have been shown to be promising in improving ART adherence and linkage to care in adults living with HIV, they have been minimally studied in YLWH. ${ }^{19}$

The existing literature on telehealth and texting platforms for HIV-related interventions for YLWH show promising results and highlights the need for additional research in this area. ${ }^{13}$ One text message medication reminder system for adolescents and YLWH was shown to be feasible, efficacious and satisfactory to participants. ${ }^{20}$ However, a study of 15- to 22-year-old YLWH found that neither a one-way or two-way text messaging intervention significantly improved HIV medication adherence. ${ }^{21}$ This highlights the need for additional research on the effectiveness of interventions that combine text messaging with other elements, which may improve efficacy.

In this paper, we describe the protocol for a study to examine the feasibility and acceptability of a novel 12-session telehealth counselling series and accompanying text messages to improve engagement in HIV care, mental health and substance use outcomes. The Youth to Telehealth and Text to Improve Engagement in Care (Y2TEC) intervention is novel in its combination of telehealth and text messaging and strategic integration of three foci (ie, engagement in HIV care, mental health and substance use). We will identify whether these methods are feasible and acceptable to YLWH and will examine preliminary clinical and behavioural outcomes of the intervention. We anticipate that Y2TEC will be feasible and acceptable for counselling YLWH and that participants will show preliminary evidence of improvement in clinical and behavioural outcomes.

\section{METHODS/DESIGN}

\section{Study overview and design}

The Y2TEC study is a single-site randomised pilot study with the primary aim of examining the feasibility and acceptability of a 12-session telehealth and text messagebased counselling series for YLWH. The secondary aim is to evaluate the preliminary impact of the intervention on improved engagement in HIV care, enhanced mental health and reduced substance use for YLWH. The University of California, San Francisco (UCSF) Institutional Review Board (IRB) has reviewed and approved this study. The intervention was designed based on the results of our formative mixed-methods and qualitative research on youth-friendly HIV counselling methods. The intervention is delivered to participants in two condition groups (ie, intervention and waitlist control) via remote telehealth sessions delivered over 4 months, with a crossover design (see table 1). The overall duration of participation is 8 months. 
Table 1 Study overview

\begin{tabular}{|c|c|c|c|c|c|c|c|c|c|}
\hline \multirow{2}{*}{$\begin{array}{l}\text { I=intervention arm participants } \\
W=\text { waitlist arm participants } \\
X=\text { all participants }\end{array}$} & \multicolumn{9}{|c|}{ Months } \\
\hline & 0 & 1 & 2 & 3 & 4 & 5 & 6 & 7 & 8 \\
\hline \multicolumn{10}{|l|}{ Screening/enrolment } \\
\hline Telephone screening & $x$ & & & & & & & & \\
\hline Informed consent & & $\mathrm{x}$ & & & & & & & \\
\hline
\end{tabular}

\section{Assessment surveys}

\begin{tabular}{lccc|}
\hline Baseline survey & X & X & X \\
Follow-up surveys & & I & W \\
$\begin{array}{l}\text { Satisfaction and acceptability } \\
\text { questionnaire }\end{array}$ & &
\end{tabular}

\section{Counselling sessions}

\begin{tabular}{|c|c|c|c|c|c|c|c|c|}
\hline Weekly counselling sessions (12) & I & 1 & 1 & 1 & W & W & W & W \\
\hline \multicolumn{9}{|l|}{$\begin{array}{l}\text { Bidirectional } \\
\text { text messages }\end{array}$} \\
\hline Monthly check-ins & & W & W & W & & 1 & 1 & I \\
\hline Session ratings & I & 1 & 1 & 1 & W & W & W & W \\
\hline Goal reminders & 1 & I & 1 & I & W & W & W & W \\
\hline $\begin{array}{l}\text { Session reminders ( } 24 \text { hours and } \\
15 \text { min before telehealth session) }\end{array}$ & 1 & 1 & I & 1 & W & W & W & W \\
\hline Community events and resources & $x$ & $x$ & $x$ & $x$ & $x$ & $x$ & $x$ & $x$ \\
\hline \multicolumn{9}{|l|}{ Exit interviews } \\
\hline Satisfaction survey & & & & 1 & & & & W \\
\hline Qualitative exit interviews & & & & I & & & & W \\
\hline
\end{tabular}

\section{Study setting}

Participants are recruited from the San Francisco Bay Area. Participants consent to the study and complete their initial baseline survey in person in a private office at a community-based location or at UCSF's Center for AIDS Prevention Studies. All other study communications are remote via the video chat platform, text messages and telephone calls.

\section{Study participants}

The study sample will consist of 80 individuals aged 18-29 years living with HIV, who live in and receive medical care in the greater San Francisco Bay Area. We have chosen to include young adults in this age range as they are in a distinct developmental phase with unique needs and challenges compared with minors or those aged older than 29 years. Other inclusion criteria include English-speaking, willing and able to provide informed consent and have access to a mobile telephone with text messaging capability. Those planning on moving out of California in the next 8 months or with evidence of severe cognitive impairment or active psychosis that may impede their ability to provide informed consent are excluded.

\section{Sample size justification}

NCSS and PASS will be used to compute the minimum detectable effect (MDE) sizes, assuming alpha $=0.05$, power $=0.80$ and $n=64$, reflecting anticipated attrition of
$20 \% .{ }^{22}$ For estimates of means and proportions for feasibility and acceptability measures, the minimum detectable distance from the estimate of the proportion to the upper or lower confidence limit is $12.7 \%$, assuming a target of $70 \%$ feasibility and acceptability. For means, the standardised distance to the limit is 0.25 . For primary preliminary outcome analyses proposed to compare means of continuous outcomes across the intervention and control groups at 4 months, the minimum detectable standardised mean difference $d$ is 0.30 . These MDEs are between cutoffs for small $(d=0.20)$ and medium $(d=0.50)$ standardised mean differences suggesting our study is powered to detect small to medium effects. ${ }^{23}$

\section{Patient and public involvement}

Prior to the design of this study, we conducted formative research with healthcare providers and patients (Saberi et al, under review), which helped us refine our research questions, study design and outcome measures. We asked YLWH about optimal methods for intervention delivery and considered the requests of several participants to have an initial session face-to-face with the counsellor. Additionally, we involve participants in study recruitment by encouraging active participants to refer others and providing a $\$ 25$ incentive to both the referee and referred. We will assess the effects and burden of the intervention by the participants themselves through our 
quantitative survey and qualitative exist interviews after the intervention. We will work with our Youth Advisory Panel and Community Action Board to disseminate the study's results to participants and the community.

\section{General study procedures}

Recruitment methods

Participants are recruited through in-person outreach at clinical and community sites serving YLWH, emails to clinics and providers, flyers posted at health clinics and community-based organisations, targeted online advertisements on Instagram, Craigslist, Facebook and Grindr and recontacting participants from prior studies who had expressed interest in being contacted about future studies. Finally, a participant referral method is used, and a \$25 incentive is provided to both the referring participant and new participant.

\section{Eligibility screening}

Study staff provide a brief overview of the study to prospective participants, answer any questions and complete an eligibility screening on the telephone. Those who meet the inclusion criteria and are willing to participate in the study are asked for a photo ID to verify their date of birth and proof of HIV status (a letter of diagnosis, laboratory results or HIV medication prescription) via a photo text-messaged to the study telephone or by bringing these documents to the initial in-person visit.

\section{Consent and enrolment procedure}

The enrolment visit will be completed in person with a study staff member. Participants review the electronic consent form (see online supplementary appendix A) with a study staff member in a private setting. Individuals who are eligible and agree to participate electronically sign the consent and a medical release form using Qualtrics (Provo, UT, USA; version March 2017) an online survey platform and are provided a copy of the Experimental Subject's Bill of Rights.

\section{Baseline survey}

Participants then complete the online baseline survey, which takes approximately $30-45 \mathrm{~min}$. Study staff then help participants download a secure video chat mobile application (ie, Zoom, a (Health Insurance Portability and Accountability Act [HIPAA]-compliant video chat platform) on their telephones. Study staff demonstrate how to set up privacy settings on mobile telephones, such as keeping text message previews from showing up on locked screens and adding a security code to lock the telephone.

\section{Randomisation}

Following the baseline survey, research staff randomly assign participants to one of two condition groups (ie, intervention or waitlist control) with a prenumbered sealed envelope. Randomisation is done using SAS (version 9.4) based on randomly permuted block sizes to ensure equal-sized groups, and all study staff are blinded to the randomisation order. Approximately 40 participants will be randomised to the immediate intervention condition and receive their first session in person; about 40 participants will be randomised to the waitlist control condition for 4 months after study enrolment and then cross-over to the treatment arm and receive the study intervention entirely remotely with no in-person session with the counsellor. The counsellor and clinical research coordinator will not be blinded to the randomisation condition, as treatment will be prescribed as a result of the condition.

\section{Participant retention}

A number of steps are taken to retain participants throughout the study period. Participants are asked for multiple forms of contact information (including emergency contacts, clinical contacts and social media contacts) at the initial visit to prevent loss of contact. They receive three monthly follow-up text messages during the waiting period to confirm their contact information, appointment reminder text messages 24 hours and 15 min before scheduled counselling sessions, birthday text messages and a weekly text message with free fun local activities to facilitate rapport-building (see table 2).

\section{Participants' Incentives}

Participants receive up to $\$ 310$ for completing all study activities, including payments for each counselling session that gradually increase throughout the study (in $\$ 10-\$ 25$ increments). Participants are given a ClinCard, a reloadable debit card and instructions for use at the initial visit. Participants are also entered into two raffles for chances to win $\$ 25$ Amazon gift cards when they confirm their contact information or answer two session rating questions after each telehealth session. Additionally, participants who refer others to the study are paid $\$ 25$ per successful recruitment.

\section{Risks to participants}

All risks to participants are monitored by study staff and documented at each session and study assessment. Study staff are trained to thoroughly explain these risks to participants as well as the steps taken to ensure privacy and confidentiality of all information. Safety-related risks to participants could include discomfort due to the sensitive nature of questions in study surveys including substance use, HIV health-related issues and mental health. Non-clinical study staff conducting interviews and participant communication refer to clinical study staff if participant distress is identified. Clinical staff delivering the intervention are trained to assess distress level of participants and refer to established protocols for any participant crisis. If a participant requires treatment due to distress, this will be determined by clinical staff; they will be referred to appropriate services following the crisis protocol, and the principal investigator (PI) will be informed. 
Table 2 Text messages

\begin{tabular}{|c|c|c|}
\hline Message & Schedule & Text and response \\
\hline 24 hours Reminder $(A)$ & $\begin{array}{l}24 \text { hours before } \\
\text { appointment }\end{array}$ & $\begin{array}{l}\text { If Y: 'Thank you for confirming, Please text us with any questions'. } \\
\text { If N: 'Thank you for replying, we will contact you to reschedule'. }\end{array}$ \\
\hline Resource (M) & As needed & $\begin{array}{l}\text { 'UCSF Team: Resources: Here are the resources you requested (link to } \\
\text { resources)'. }\end{array}$ \\
\hline Free Stuff (A) & Weekly & $\begin{array}{l}\text { 'UCSF Team: Fun Free Stuff: Enjoy Free Yoga in the Park this Saturday from } \\
10 \text { to } 11 \text { am, Downtown Oakland. Here's the link (website)'. }\end{array}$ \\
\hline Monthly Check-in* (A) & $\begin{array}{l}\text { Monthly during waiting } \\
\text { period }\end{array}$ & $\begin{array}{l}\text { 'UCSF Study Team: Update or confirm your contact info for a chance to win } \\
\text { one of } 5 \$ 25 \text { Amazon e- Gift cards at the end of the study. Has your phone } \\
\text { number or email address changed? Please reply } \\
1 \text { Yes } \\
0 \text { No' } \\
\text { If yes: 'Please send us your updated phone number and email } \\
\text { address. } \\
\text { luck!' If No: Thank you! You have been entered in the raffle, good luck!' }\end{array}$ \\
\hline Survey Link (M) & $\begin{array}{l}\text { Baseline, } 4 \text { and } \\
8 \text { months }\end{array}$ & $\begin{array}{l}\text { 'UCSF Team: It's time for your survey. Click on the link below to complete } \\
\text { the feedback survey and receive } \$ 10 \text {. Thank you! (Survey Link)' }\end{array}$ \\
\hline Session Rating* $(A)$ & After each session & $\begin{array}{l}\text { 'UCSF Team: Please tell us about the session today for a chance to win one } \\
\text { of five } \$ 25 \text { Amazon e-Gift cards at the end of the study: } \\
1 \text { - I felt heard, understood, and respected by the counselor: } \\
\text { a. Strongly agree } \\
\text { b. Agree } \\
\text { c. Neither agree nor disagree } \\
\text { d. Disagree } \\
\text { e. Strongly disagree } \\
2 \text { - Overall, today's session was right for me: } \\
\text { a. Strongly agree } \\
\text { b. Agree } \\
\text { c. Neither agree nor disagree } \\
\text { d. Disagree } \\
\text { e. Strongly disagree' } \\
\text { Response: 'Thanks for your responses! Please let us know if you have any } \\
\text { additional comments by texting us'. }\end{array}$ \\
\hline Session Completion (M) & $\begin{array}{l}\text { After completion of all } \\
\text { sessions }\end{array}$ & $\begin{array}{l}\text { 'Congratulations on completing the } 1 \text { st half of the Y2TEC study! Next, you } \\
\text { will receive a survey on } x x / x x / x x \& \text { a final survey on yy/yy/yy. Please let us } \\
\text { know if you have any questions. Thanks!' }\end{array}$ \\
\hline $\begin{array}{l}\text { Waiting Period } \\
\text { Completion (M) }\end{array}$ & $\begin{array}{l}\text { After completing waiting } \\
\text { period }\end{array}$ & $\begin{array}{l}\text { 'Congratulations, you have finished the } 1 \text { st half of the Y2TEC study! Next, } \\
\text { you will receive a survey on } x x / x x / x x \& \text { we will contact you to schedule your } \\
1 \text { st video chat session after you complete your survey. Please let us know if } \\
\text { you have any questions. Thanks!' }\end{array}$ \\
\hline Birthday Message (M) & $\begin{array}{l}\text { On participant's } \\
\text { birthday }\end{array}$ & $\begin{array}{l}\text { 'UCSF Team: Happy Birthday, we are sending you all our best wishes for a } \\
\text { very happy birthday today, cheers!' }\end{array}$ \\
\hline Away Message (A) & After hours and holidays & $\begin{array}{l}\text { 'Thank you for your message! The Y2TEC Study staff are out of the office } \\
\text { until XX/XX/XX and will respond after this date. If this is an emergency, } \\
\text { please call 911.' }\end{array}$ \\
\hline Study Referral (M) & As needed & $\begin{array}{l}\text { 'UCSF Team: Participants can receive up to } \$ 310 \text { for completing all study } \\
\text { activities plus } \$ 25 \text { per person they refer who enrolls in the study!' }\end{array}$ \\
\hline
\end{tabular}

*Bidirectional.

$(A)=$ Automated message.

$(M)=$ Manually sent message. 


\section{Adverse events and auditing}

The study staff monitor postsession participant ratings (via text message) as one method for identifying those who may have experienced an adverse event. If a participant reports low satisfaction with the intervention, study staff contact them in a timely manner to determine what occurred in the session. Study staff also provide participants with the study mobile telephone number to spontaneously report any adverse events or unintended effects of the intervention. Any adverse events will be documented on an adverse event form, and follow-up will be tracked. The form along with any session notes with details will be reported to the IRB by the PI within 10 working days. The team of investigators will also meet weekly to audit and discuss general trial conduct-related issues.

\section{Protocol amendments}

Protocol amendments will be shared with all stakeholders as they occur. Study staff communicate protocol modifications to investigators during monthly meetings, submit changes to www.clinicaltrials.gov as needed, submit IRB modifications and communicate changes to regulators during meetings every 6 months or via email as needed.

\section{Intervention procedure}

The 12-session telehealth series is delivered by a trained behavioural health professional (such a social worker, psychologist or psychotherapist), referred to as the 'counsellor' within the context of this study. Sessions use problem-solving, information-motivation-behavioural skills and motivational interviewing and focus on engagement in HIV care, mental health and substance use. ${ }^{24-26}$ Telehealth sessions are completed via a secure video chat platform, Zoom, and text messages are sent via a secure encrypted, HIPAA-compliant platform called Mosio.

\section{Series overview}

Participants in the intervention arm meet with the counsellor in person immediately after enrolment, and the waitlist control arm participants meet with the counsellor via video chat after 4 months. Before the first meeting, the counsellor reviews the participant's most recent assessment survey responses to determine the participant's level of acuity and tailor appropriate session dosage. Mental health acuity is determined through the Patient Health Questionnaire (PHQ) 9 and PTSD Checklist (PCL); substance use acuity is determined through the Alcohol Use Disorders Identification Test (AUDIT) and Alcohol, Smoking and Substance Involvement Screening Test (ASSIST); HIV care acuity is calculated by a measure of HIV knowledge as well as current participant utilisation of HIV care services and antiretroviral medications. During the first session, the counsellor assesses the participant's needs and identifies current gaps in knowledge and motivation regarding mental health, substance use and HIV care. The first three to six of the remaining 11 sessions cover core psychoeducational and health literacy-promoting content around engagement in HIV care, mental health and substance use challenges and treatments. Those with higher acuity receive two foundational psychoeducational modules rather than one in each of the three areas, amounting to a maximum of six core educational sessions.

The remaining sessions use an integrated behavioural health and HIV care- focused approach to further the conversations initiated in the core sessions. At the beginning of these sessions, the participant and counsellor choose from a list of topics identified in the first session, including HIV care, mental health, substance use, lifestyle health, social support, family of origin, romantic and sexual relationships, self-identity and disclosure, subsistence needs (housing, money and resources) and education and vocation. These sessions can be done in any order and repeated as needed. If a participant is in crisis and unable to be redirected to these options, a 'wildcard' session focused on crisis response and safety planning may be held. The final session includes reviewing the content covered and goals achieved in the previous sessions, identifying unmet needs, accessing community-based resources and learning strategies for maintaining changes.

\section{Scheduling sessions}

Four months are allocated to complete the 12 weekly counselling sessions to allow for missed and rescheduled sessions. Participants are encouraged to contact the counsellor or study staff to reschedule their appointments as needed. Participants receive session reminders via text message 24 hours and $15 \mathrm{~min}$ before each session.

\section{Session documentation and fidelity}

The counsellor completes session summary notes through a Qualtrics survey form, which includes closed-ended and multiple-choice questions such as session length, participant location, technical issues encountered, session topics selected, educational topics covered, goals set, a session content fidelity checklist and a narrative progress note.

\section{Evaluation and curriculum modifications}

The initial version of the Y2TEC intervention will be delivered to participants randomised to the intervention arm. The research team plans to adjust the intervention based on lessons learnt and feedback from participants to develop a modified version of the intervention (ie, intervention manual version 2.0). This version will be provided to all waitlist control participants, and outcome differences between the two arms will be explored during analysis. As a result, the intervention will have gone through an iterative refinement process and will be ready for implementation in a larger randomised controlled trial by the end of the pilot study.

\section{Data collection and management procedure Clinical data collection}

At consent, participants sign a medical release form, and research staff obtain medical records from participants' respective medical clinics at baseline, 4 months and 8 months. Information collected includes appointment 
Table 3 Measures in participant surveys

\begin{tabular}{|c|c|c|c|}
\hline $\begin{array}{l}\text { Domain (in order of the } \\
\text { survey) }\end{array}$ & Measure & Baseline survey & Follow-up surveys \\
\hline Demographics & Original measure & $x$ & \\
\hline $\begin{array}{l}\text { HIV treatment outcomes, } \\
\text { antiretroviral history and } \\
\text { adherence }\end{array}$ & Original measure & $x$ & $x$ \\
\hline Alcohol use & Alcohol Use Disorders Identification Test ${ }^{35}$ & $x$ & $x$ \\
\hline Substance use & $\begin{array}{l}\text { Alcohol, Smoking and Substance } \\
\text { Involvement Screening Test }{ }^{36} \mathrm{Q} 2 \\
\text { Drug Abuse Screening Test- } 10^{37}\end{array}$ & $x$ & $x$ \\
\hline Depression & Patient Health Questionnaire- $9^{38}$ & $x$ & $x$ \\
\hline Anxiety & Generalised Anxiety Disorder- $7^{41}$ & $X$ & $x$ \\
\hline Sleep & Pittsburgh Sleep Quality Index) ${ }^{42}$ & $x$ & $x$ \\
\hline Resilience & Connor-Davidson Resilience Scale ${ }^{43}$ & $x$ & $x$ \\
\hline Internalised HIV stigma & HIV Stigma Mechanisms ${ }^{44}$ & $\mathrm{X}$ & $x$ \\
\hline $\begin{array}{l}\text { Mental health and substance } \\
\text { use stigma }\end{array}$ & $\begin{array}{l}\text { SAMHSA Mental Health and Alcohol } \\
\text { Abuse Stigma Assessment }{ }^{45}\end{array}$ & $X$ & $X$ \\
\hline Social support & $\begin{array}{l}\text { Medical Outcomes Study Social Support } \\
\text { Scale }^{46}\end{array}$ & $x$ & $x$ \\
\hline Social isolation & $\begin{array}{l}\text { Patient-Reported Outcomes Measurement } \\
\text { Information System }{ }^{47}\end{array}$ & & $X$ \\
\hline
\end{tabular}

PTSD, posttraumatic stress disorder; SAMHSA, Substance Abuse and Mental Health Services Administration.

attendance, medications and laboratory data including plasma HIV RNA and CD4+ cell count. The data point closest to baseline, 4 months and 8 months \pm 1 month are used for data analysis.

Assessment data collection

Participants complete assessment surveys at baseline, 4 months and 8 months after enrolment. The surveys collect demographic, technology use, substance use, mental health and HIV care information (see table 3). The baseline surveys are completed online in-person at the initial visit, and the other two are completed remotely on the participants' mobile devices.

Qualitative data collection

A subset of approximately 20 participants who have finished the intervention will be invited to complete an audio-recorded telephone semistructured individual qualitative exit interview with study staff for a $\$ 30$ payment. Participants will be chosen to reflect a range of levels of engagement and attendance using a question adapted from the Session Rating Scale ${ }^{27}$ to determine the level of satisfaction with each telehealth session. Using mean scores of participant satisfaction over 12 telehealth sessions and attendance, participants will be divided into four groups: (1) high attendance, high satisfaction; (2) high attendance, low satisfaction; (3) low attendance, high satisfaction; and (4) low attendance, low satisfaction. Five participants will be randomly selected from each category and interviewed. Participants will receive information and consent for the qualitative interviews during the initial visit, along with the consent for the rest of the study. The interviews will focus on the acceptability of the intervention and participant feedback on the intervention, and the interviews will be audio- recorded and transcribed verbatim. 
Table 4 Primary outcome measures: feasibility and acceptability

\begin{tabular}{|c|c|c|}
\hline $\begin{array}{l}\text { Primary outcome } \\
\text { measures }\end{array}$ & Metrics & Acceptance criteria \\
\hline \multirow[t]{2}{*}{ Acceptability } & $\begin{array}{l}\text { Measure participant satisfaction with the telehealth } \\
\text { intervention at completion of intervention by a } 30 \text { - } \\
\text { item questionnaire ( } 1 \text { excellent to } 6 \text { unsatisfied) } \\
\text { administered through an online survey }\end{array}$ & Mean satisfaction score $\geq 80 \%$ \\
\hline & $\begin{array}{l}\text { Measure participant satisfaction with each } \\
\text { telehealth session via } 2 \text {-item scale ( } 1 \text { strongly } \\
\text { agree to } 4 \text { strongly disagree) administered via text } \\
\text { messaging }\end{array}$ & $\begin{array}{l}\text { Mean satisfaction score } \geq 80 \% \text { over } 12 \text { telehealth } \\
\text { sessions }\end{array}$ \\
\hline \multirow[t]{5}{*}{ Feasibility } & Recruitment & $\begin{array}{l}\text { At least } 70 \% \text { of the planned } 80 \text { participants (ie, } \\
n=56 \text { ) }\end{array}$ \\
\hline & Participant retention at 4 months & $\begin{array}{l}\text { At least } 80 \% \text { of participants retained in the study at } \\
4 \text { months }\end{array}$ \\
\hline & Participant response time to texts & $\begin{array}{l}\text { Mean of } 3 \text { days between bidirectional text message } \\
\text { and participants' response }\end{array}$ \\
\hline & $\begin{array}{l}\text { Sound quality based on a one item questions } \\
\text { using Likert scale }(0-10)(0=\text { poor quality; } \\
10=\text { excellent quality) as rated by counsellor }\end{array}$ & Mean of 7 out of 10 sound quality \\
\hline & $\begin{array}{l}\text { Video quality based on a one item question } \\
\text { using Likert scale }(0-10)(0=\text { poor quality; } \\
10=\text { excellent quality) as rated by counsellor }\end{array}$ & Mean of 7 out of 10 video quality \\
\hline
\end{tabular}

\section{Confidentiality and data protection}

All screening and consenting will take place in a private room. Study staff will use a secure, encrypted texting platform for all study text communication. Participants will receive support from study staff who will demonstrate how to set up additional privacy measures using the settings on their personal mobile telephones. Electronic data will be gathered through HIPAA-compliant platforms, stored on a secure network and password protected. Subjects will be coded by numbers and with no names; linking information will be kept in locked files. The data will not be shared unless via a data use agreement including deidentified data. The study has obtained a Certificate of Confidentiality from the National Institutes of Health to protect the privacy of potential and enrolled study participants.

\section{Data monitoring}

A Data Monitoring Committee (DMC), interim analyses and stopping guidelines are not needed because the study is a pilot feasibility study that has been classified as minimal risk by the UCSF IRB.

\section{Study outcomes}

Feasibility, acceptability and clinical outcomes

Preliminary data on feasibility, acceptability and HIV clinical outcomes will be gathered throughout the study (see tables 4 and 5). Acceptability of the telehealth intervention will be determined throughout the study using several methods. Study staff will administer two-session rating questions via text after each weekly telehealth session, asking if the participant 'felt heard, understood and respected by the counsellor' and if the 'session was right' for them. Additionally, a 30-item exit survey is administered through Qualtrics after the intervention is completed, including questions pertaining to (1) the overall rating of the study; (2) satisfaction with each study procedure; (3) ease or difficulty with each study procedures; (4) helpfulness of communication with study staff; (5) self-perception of improved ART adherence, mental health and substance use with study participation; (6) recommending a study similar to this to a friend; and (7) participating again in a similar study. Study staff will also conduct qualitative exit interviews with 20 participants to gather in-depth descriptions of participant experiences, perceptions and acceptability of the intervention. Clinical outcomes within the two study arms include HIV RNA, CD4+ cell count, self-reported adherence, appointment attendance, substance use (Drug Abuse Screening Test [DAST] and ASSIST) and mental health (PHQ-9 and PCL-5; see table 5).

\section{Data analysis plan}

Quantitative analysis plan

One-way frequency tables will be generated for all baseline and follow-up survey questions, and measures of central tendency and variability will be computed for continuous measures. Results from these analyses will 
Table 5 Secondary outcome measures: clinical impact

\section{Secondary outcome measures}

Alcohol use

Depression

\section{Metrics}

Measure participants' alcohol use from baseline to 4 and 8 months using the Alcohol Use Disorder Test (AUDIT), a 10-item questionnaire to measure severity of participants' alcohol use. Responses are summed. Scoring range is 0-20+; 0-7: Low alcohol use, 8-19: Moderate alcohol use, 20+: High alcohol use/dependence.

Measure participants' depression from baseline to 4 and 8 months using the Patient Health Questionnaire 9, a 9-item Likert scale score (0-3) 0 'not at all', 3 'nearly every day'. Responses are summed. Scores will have a range of 0-27. PHQ-9 scores of $>10$ are associated with moderate to severe depression.

Frequency of Substance Use
Posttraumatic stress disorder
(PTSD)

Measure participants' change in substance use from baseline to 4 and 8 months using a 10 item questionnaire (ASSIST) to measure frequency of participants' substance use.

Measure participants' self-reported PTSD from baseline to 4 and 8 months using the PTSD Checklist-revised, a 20-item Likert questionnaire administered through an online survey. Scoring: 0 points for 'not at all', 1 point for 'a little bit', 2 points for 'moderately', 3 points for 'quite a bit', 4 points for 'extremely'. Scores will have a range of 0-80. Responses are summed.

\begin{tabular}{|c|c|}
\hline $\begin{array}{l}\text { Self-reported medication } \\
\text { adherence }\end{array}$ & $\begin{array}{l}\text { Measure changes in participants' self-reported medication adherence based on } 1 \text {-item } \\
\text { adherence rating ( } 1 \text { excellent to } 6 \text { poor, lower rating indicates higher adherence) from baseline } \\
\text { to } 4 \text { and } 8 \text { months. }\end{array}$ \\
\hline Severity of substance use & $\begin{array}{l}\text { Measure participants' changes in substance use from baseline to } 4 \text { and } 8 \text { months using the } \\
\text { Drug Abuse Screening Test, a 10-item questionnaire to measure severity of participants' } \\
\text { substance use. Responses are summed. Scoring (0-10); 0-2 low substance use, 9-10 severe } \\
\text { substance use. }\end{array}$ \\
\hline $\begin{array}{l}\text { Measure of participant HIV } \\
\text { knowledge using HIV Treatment } \\
\text { Knowledge Scale }\end{array}$ & $\begin{array}{l}\text { Assess participants' knowledge of HIV from baseline to } 4 \text { and } 8 \text { months through the HIV } \\
\text { Treatment Knowledge measure, a 15-item self-report questionnaire. Scoring out of } 15 \text { (0-12 } \\
\text { inadequate, and } 13-15 \text { adequate). Scores will have a range of } 0-15 \text {. }\end{array}$ \\
\hline
\end{tabular}

ASSIST, Alcohol, Smoking and Substance Involvement Screening Test .

quantify important sample characteristics and participant use of various telehealth modalities as well as proportions and means of the feasibility and acceptability measures. Primary preliminary outcome analyses will use linear mixed models to compare mean $\log 10$ HIV RNA across the intervention and control groups at 4 months relative to baseline. Secondary exploratory preliminary outcome analyses will use the same analytic methods to compare the 8-month time point within the intervention arm to baseline to examine whether the intervention had longerterm effects. A parallel exploratory analysis will compare waitlist controls at 4 months versus 8 months.

Additional secondary exploratory analyses will repeat this set of analyses on other secondary outcomes such as CD4+ cell count, HIV knowledge, self-reported adherence and appointment attendance, PHQ-9 and PCL-5 mental health measures, AUDIT alcohol use measure and the DAST substance use measure. Finally, all analyses described above will be repeatedly stratified by participant gender to explore whether there is any evidence of gender differences in effects. Due to the modest sample size and pilot focus of the study, significance testing will be de-emphasised in favour of performing inferential analyses as a feasibility check to ensure all measures and analysis protocols are in place for a larger formal efficacy trial. $^{2829}$

\section{Qualitative analysis plan}

Study staff will complete, audio- record and transcribe individual in-depth interviews with $20 \mathrm{YLWH}$ following completion of the clinical intervention. The analytic team will identify broad themes from the interview transcripts, discuss and refine them and then enter them into a Microsoft Excel-based matrix with a column for each theme and a row for each case. One coder will initially identify patterns in the themes and code each interview to identify subthemes, and a second coder will double code a random subsample $(n=5)$ of the interview codes within the matrix. Discrepancies in coding will be discussed by the team until a consensus is reached and interrater reliability will be calculated. A sequential mixed-method design will be used to integrate our quantitative and qualitative data analysis.

\section{Dissemination plan}

Study staff will work with the UCSF Centre for AIDS Prevention Studies' Community Engagement Core and the Youth Advisory Board to disseminate results to the community and participants via presentations, community forums, email updates and/or social media. Study staff will conduct town hall presentations and publish findings in peer-reviewed journals to communicate results with healthcare professionals. 


\section{DISCUSSION}

This study protocol describes the Y2TEC pilot, randomised, cross-over study designed to impact the mental health, substance use and HIV care challenges of YLWH. Few interventions for YLWH currently exist that address these three concerns in an integrated way, and as a result, we had few examples of similar curricula while developing the Y2TEC intervention. Therefore, we relied on formative research including qualitative interviews with healthcare providers and staff serving YLWH, as well as a mixed-methods study examining HIV care engagement, mental health, substance use and technology-based interventions to address these issues with the target population [Saberi et al, under review, ${ }^{15}$ ].

Additionally, in our review of existing telehealth interventions focusing on these areas, we discovered that there were general telehealth guidelines but few specifics for research. For example, telehealth-specific regulations on best practices for responding to mental health crises described general practices for clinicians with little mention of best clinical practices for crisis response within a research setting. ${ }^{31}$ We also found that there were few sources of information about best practices for using text messaging and telehealth counselling within research settings, as many healthcare providers who are currently holding telehealth appointments are practicing within medical groups that have officially adopted these technologies. $^{32}$

This study has several unique aspects that are worth highlighting. This intervention explores non-traditional methods for care provision that deviate from the adult-care models and may be considered more 'youth friendly'. ${ }^{33}$ The intervention was specifically designed to be tailored and adaptable to the participant using the results of the participant's assessment responses to inform the counsellor's decision-making around the number of educational and problem-solving sessions on particular topics. As a result, the counsellor is given the ability to spend more or less time on HIV care, mental health or substance use based on the acuity of the participant's need. Though this adaptive modular structure adds complexity, it has the potential to better meet the needs of participants than a more rigidly structured intervention.

Furthermore, this study simultaneously explores several unique aspects of feasibility and acceptability. In addition to exploring whether this form of intervention will impact HIV, mental health and substance use outcomes, we are also considering the acceptability of a fully online versus hybrid in-person online session delivery. Half of the participants receive the first intervention session with the counsellor in person and the rest of their sessions remotely, and the other half receive the full series remotely. If shown to be similarly acceptable, this intervention can be offered completely remotely.

The Y2TEC counselling series has been designed with replication and scalability in mind. The intervention is unique in the relatively low clinician time burden (6 hours of individual counselling per participant over 4 months) compared with traditional face-to-face counselling, which often involves weekly hour-long sessions (which may total 12-16 hours over 4 months). Additionally, if we find that participants perceive the remote-only counselling option as acceptable, implementing the intervention would require minimal office space and physical materials, limiting factors within healthcare settings. A remote-only counselling intervention would also potentially increase access for those living in rural areas with limited access to transportation or local services.

We anticipate that the findings of our study will show that a telehealth and text message-based counselling series for YLWH will be acceptable and feasible. We expect that the findings from this study will provide information about additional ways of using new mobile technologies to support the HIV care goals and behavioural health needs of YLWH and will help influence the development of additional mobile-based counselling strategies. The results of this pilot study will allow us to conduct a larger multicentre randomised controlled trial to examine the efficacy of this intervention.

\section{Author affiliations}

${ }^{1}$ Department of Medicine, Center for AIDS Prevention Studies, University of California, San Francisco, San Francisco, California, USA

${ }^{2}$ Department of Psychiatry, University of California, San Francisco, San Francisco, USA

${ }^{3}$ School of Nursing, Department of Community Health Systems, University of California, San Francisco, San Francisco, California, USA

Acknowledgements The authors would like to thank the participants of the prior Youth to Telehealth and Text to Improve Engagement in Care (Y2TEC) formative study and the Youth Advisory Panel for their input on this study. The authors would like to acknowledge Konadu Fokuo and Caravella McCuistian for their clinical consultation and feedback on the Y2TEC intervention. The authors would like to acknowledge Samantha Dilworth for her assistance with developing the randomisation protocol.

Contributors PS, CDR and MOJ conceived the study and developed the experimental design and measures. ARW and VAG developed the telehealth counselling intervention and manual. DAL and PS developed the main study protocols. ARW and DAL carried out the daily study activities. TBN contributed to the data collection and analysis plan. All authors were involved in the revision of the draft manuscript and have agreed to the final content.

Funding Research reported in this publication was supported by the California HIV/ AIDS Research Program (CHRP) award number HD15-SF-060 (co-Pls Saberi and Dawson Rose) and the National Institutes of Health award number K24DA037034 (Johnson). The National Institutes of Health and Cancer Disparities Research Partnership have reviewed, approved and have no role in this study besides financial support.

Competing interests None declared.

Patient consent for publication Not required.

Ethics approval University of California, San Francisco IRB \# 16-18538.

Provenance and peer review Not commissioned; externally peer reviewed.

Open access This is an open access article distributed in accordance with the Creative Commons Attribution Non Commercial (CC BY-NC 4.0) license, which permits others to distribute, remix, adapt, build upon this work non-commercially, and license their derivative works on different terms, provided the original work is properly cited, appropriate credit is given, any changes made indicated, and the use is non-commercial. See: http://creativecommons.org/licenses/by-nc/4.0/. 


\section{REFERENCES}

1. CDC. HIV among youth. 2018 https://www.cdc.gov/hiv/group/age/ youth/index.html (Retrieved 4 Jun 2018).

2. Zanoni BC, Mayer $\mathrm{KH}$. The adolescent and young adult HIV cascade of care in the United States: exaggerated health disparities. AIDS Patient Care STDS 2014;28:128-35.

3. Chesney MA. The elusive gold standard. Future perspectives for HIV adherence assessment and intervention. J Acquir Immune Defic Syndr 2006;43(Suppl 1):S149-55.

4. World Health Organization. Adherence to long-term therapies: evidence for action. Geneva: World Health Organization, 2003.

5. Cohen MS, Chen YQ, McCauley M, et al. Prevention of HIV1 infection with early antiretroviral therapy. $N$ Engl J Med 2011;365:493-505.

6. Brown LK, Whiteley L, Harper GW, et al. Psychological Symptoms Among 2032 Youth Living with HIV: A Multisite Study. AIDS Patient Care STDS 2015;29:212-9.

7. Whiteley LB, Brown LK, Swenson R, et al. Disparities in mental health care among HIV-infected youth. J Int Assoc Provid AIDS Care 2014;13:29-34.

8. Gamarel KE, Brown L, Kahler CW, et al. Prevalence and correlates of substance use among youth living with HIV in clinical settings. Drug Alcohol Depend 2016;169:11-18.

9. MacDonell K, Naar-King S, Huszti H, et al. Barriers to medication adherence in behaviorally and perinatally infected youth living with HIV. AIDS Behav 2013;17:86-93.

10. Fortenberry JD, Martinez J, Rudy BJ, et al. Linkage to care for HIVpositive adolescents: a multisite study of the adolescent medicine trials units of the adolescent trials network. J Adolesc Health 2012;51:551-6.

11. Uthman OA, Magidson JF, Safren SA, et al. Depression and adherence to antiretroviral therapy in low-, middle- and high-income countries: a systematic review and meta-analysis. Curr HIVIAIDS Rep 2014;11:291-307.

12. Brown LK, Whiteley L, Harper GW, et al. Psychological symptoms among 2032 youth living with HIV: a multisite study. AIDS Patient Care STDS 2015;29:212-9.

13. Reisner SL, Mimiaga MJ, Skeer M, et al. A review of HIV antiretroviral adherence and intervention studies among HIV-infected youth. Top HIV Med 2009;17:14-25.

14. Smith A. U.S. Smartphone Use in 2015. 2015. Available at www. pewinternet.org/2015/04/01/us-smartphone-use-in-2015.

15. Saberi $P$, Yuan $P$, John $M$, et al. A pilot study to engage and counsel HIV-positive African American youth via telehealth technology. AIDS Patient Care STDS 2013;27:529-32.

16. Saberi P, Siedle-Khan R, Sheon N, et al. The Use of Mobile Health Applications Among Youth and Young Adults Living with HIV: Focus Group Findings. AIDS Patient Care STDS 2016;30:254-60.

17. Salesforce. State of the Connected Patient. 2015 https:// www. salesforce.com/form/industries/2015-state-connected-patient.jsp (Retrieved 4 Jun 2018).

18. Hightow-Weidman LB, Muessig KE, Bauermeister J, et al. Youth, Technology, and HIV: Recent Advances and Future Directions. Curr HIVIAIDS Rep 2015;12:500-15.

19. Haberer JE, Sabin L, Amico KR, et al. Improving antiretroviral therapy adherence in resource-limited settings at scale: a discussion of interventions and recommendations. J Int AIDS Soc 2017;20:21371.

20. Garofalo R, Kuhns LM, Hotton A, et al. A Randomized Controlled Trial of Personalized Text Message Reminders to Promote Medication Adherence Among HIV-Positive Adolescents and Young Adults. AIDS Behav 2016;20:1049-59.

21. Linnemayr S, Huang HC, Luoto J, et al. Text messaging for improving antiretroviral therapy adherence, 2017.

22. Hintze J. NCSS PASS 16 (Version 14). Kaysville, Utah: NCSS Statistical Software, 2018.

23. Cohen J. Statistical power analysis for the behavioral sciences. Hillsdale, New Jersey: Lawrence Erlbaum Associates, 1987.

24. Nezu AM, Maguth Nezu C, D'Zurilla TJ. Problem-solving therapy: a treatment manual. New York, NY, US: Springer Publishing Co, 2013.

25. Rapp C. The Strengths Model: Case Management with People Suffering from Severe and Persistent Mental IIIness. 1st Ed. New York: Oxford University Press, 1997.

26. Miller WR, Rollnick S. Motivational interviewing: preparing people to change: Guilford press, 2002.
27. Duncan BL, Miller SD, Sparks JA, et al. The Session Rating Scale: Preliminary psychometric properties of a "working" alliance measure. Journal of brief Therapy 2003;3:3-12.

28. Kraemer HC, Mintz J, Noda A, et al. Caution regarding the use of pilot studies to guide power calculations for study proposals. Arch Gen Psychiatry 2006;63:484-9.

29. Leon AC, Davis LL, Kraemer HC. The role and interpretation of pilot studies in clinical research. J Psychiatr Res 2011;45:626-9.

30. National Association of Social Workers. (n.d.). [Brochure]. Author. https://www.aswb.org/announcements/technology-standards-insocial-work-practice (Retrieved 11 Oct 2018).

31. Turvey C, Coleman M, Dennison O, et al. Telemedicine and e-Health. 2013 http://doi.org/10.1089/tmj.2013.9989.

32. National Association of Social Workers, Association of Social Work Boards, Council on Social Work Education, \& Clinical Social Work Association. Standards for Technology in Social Work Practice [Pamphlet]: National Association of Social Workers, 2017.

33. Saberi P, Ming K, Dawson-Rose C. What does it mean to be youth-friendly? Results from qualitative interviews with health care providers and clinic staff serving youth and young adults living with HIV. Adolesc Health Med Ther 2018;9:65-75.

34. Balfour L, Kowal J, Tasca GA, et al. Development and psychometric validation of the HIV Treatment Knowledge Scale. AIDS Care 2007;19:1141-8.

35. Bohn MJ, Babor TF, Kranzler HR. The Alcohol Use Disorders Identification Test (AUDIT): validation of a screening instrument for use in medical settings. J Stud Alcohol 1995;56:423-32.

36. Humeniuk R, Henry-Edwards S, Ali R, et al. The ASSIST-linked brief intervention for hazardous and harmful substance use: a manual for use in primary care: World Health Organization, 2010.

37. Skinner HA. The drug abuse screening test (DAST): Guidelines for Administration and Scoring. Toronto: Addiction Research Foundation, 1982.

38. Spitzer RL, Kroenke K, Williams JB. Validation and utility of a selfreport version of PRIME-MD: the PHQ primary care study. Jama 1999;282:1737-44.

39. Dube SR, Felitti VJ, Dong M, et al. Childhood abuse, neglect, and household dysfunction and the risk of illicit drug use: the adverse childhood experiences study. Pediatrics 2003;111:564-72.

40. Weathers FW, Litz BT, Keane TM, et al. The ptsd checklist for dsm-5 (pcl-5). Scale. 2013.

41. Spitzer RL, Kroenke K, Williams JB, et al. A brief measure for assessing generalized anxiety disorder: the GAD-7. Arch Intern Med 2006;166:1092-7.

42. Buysse DJ, Reynolds CF, Monk TH, et al. The Pittsburgh Sleep Quality Index: a new instrument for psychiatric practice and research. Psychiatry Res 1989;28:193-213.

43. Connor KM, Davidson JR. Development of a new resilience scale: the Connor-Davidson Resilience Scale (CD-RISC). Depress Anxiety 2003;18:76-82

44. Tsai AC, Weiser SD, Steward WT, et al. Evidence for the reliability and validity of the internalized AIDS-related stigma scale in rural Uganda. AIDS Behav 2013;17:427-33.

45. King-Kallimanis BL, Oort FJ, Lynn N, et al. Testing the assumption of measurement invariance in the samhsa mental health and alcohol abuse stigma assessment in older adults. Ageing Int 2012;37:441-58

46. Sherbourne CD, Stewart AL. The MOS social support survey. Soc Sci Med 1991;32:705-14.

47. Cella D, Riley W, Stone A, et al. The Patient-Reported Outcomes Measurement Information System (PROMIS) developed and tested its first wave of adult self-reported health outcome item banks: 2005 2008. J Clin Epidemiol 2010;63:1179-94.

48. Gagnon M, Hibert R, Dubé M, et al. Development and validation of an instrument measuring individual empowerment in relation to personal health care: the Health Care Empowerment Questionnaire (HCEQ). Am J Health Promot 2006;20:429-35.

49. Bakken S, Holzemer WL, Brown MA, et al. Relationships between perception of engagement with health care provider and demographic characteristics, health status, and adherence to therapeutic regimen in persons with HIV/AIDS. AIDS Patient Care STDS 2000;14:189-97.

50. Ware JE, Sherbourne CD. The MOS 36-item short-form health survey (SF-36). I. Conceptual framework and item selection. Med Care $1992 ; 30: 473-83$ 